mediastudies.press • Social Media \& the Self: An Open Reader

\title{
Shape Shifting Across Social Media
}

Brittany I. Davidson' ${ }^{1}$, Adam N. Joinson ${ }^{1}$

${ }^{1}$ University of Bath

Published on: Feb 18, 2021

DOI: $10.32376 / 3 f 8575 c b . d 8 e 1 a 45 b$

License: Creative Commons Attribution 4.0 International License (CC-BY 4.0). 


\begin{abstract}
Individuals change and adapt their behavior according to their social situation (e.g., transitioning from work to home). However, how does this shape shifting of selfpresentations and identity translate into various online platforms? This exploratory study utilizes a novel and mixed methodological approach to better understand user behavior across social media platforms. We interviewed 22 participants and employed a repertory grid technique to reveal deeper similarities and differences in behavior across various online platforms. We found that users had a variety of strategies for managing multiple audiences across multiple platforms. Almost all participants actively separated their professional (e.g., LinkedIn) and social (e.g., Facebook or Instagram) oriented platforms typically by self-censorship of posts rather than utilizing audience management tools. Via the repertory grid technique, we revealed a number of more subtle nuances of how participants reflect on how and why they maintain a number of social media identities.
\end{abstract}

Keywords: social media, online identity, repertory grids, self-presentation, audience management

\title{
Introduction
}

You have one identity. [. . .] The days of you having a different image for your work friends or co-workers and for the other people you know are probably coming to an end pretty quickly. - Mark Zuckerberg, as reported by Zimmer (2010).

HUMANS ARE FUNDAMENTALLY social beings-something that has continued and become accentuated-as the world has become increasingly digitized (e.g., Dellarocas, 2003; Loebbecke \& Picot,2015). A key part to this sociality is our ability to change and adapt our behavior in response to both internal (e.g., emotion, expectations) and

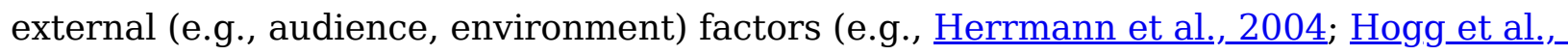
1995). This social flexibility extends to our behavior across contexts-we would not expect a person to behave identically as they transit from work to home, or from home to a night-out with friends. This type of context-based behavioral change is normal and expected by those around us (e.g., Fiske,2010; Herrmann et al.,2004). This may also seen in an online context, where a user will behave differently as they move from one online system to another. For example, the same colleague may be inclined to present themselves differently on LinkedIn compared to on Facebook, while their Tinder profile may be more different again. Indeed, there is some limited evidence for this-for instance, Vasalou and Joinson (2009). found that users were likely to create a more 
attractive avatar for a dating profile and a more "intellectual looking" avatar for an online gaming profile. This does not mean that online identity is in someway not "authentic" or "genuine," but rather that identity is itself dynamic and changing (Kasperiuniene \& Zydziunaite,2019) with different elements drawn into use according to the context and ongoing interaction.

Hence, for many users, social media is a diverse experience. Users may have distinct audiences across assorted services and, perhaps, manage multiple personal and organizational identities on those same sites and applications (Kasperiuniene \& Zydziunaite, 2019). However, while most individuals usually able to easily manage diverse audiences and maintain a separate work-life balance, this is becoming increasingly difficult online, especially in an age where social media platforms have become ever more interlinked and ubiquitous. Even once separate services (e.g., WhatsApp, Instagram) are now parts of a single organization (Facebook), often with shared authentication and access routes, merged content, and contacts suggested from one platform to the next. Indeed, in early 2019, Facebook merged communication across Facebook Messenger, Instagram, and WhatsApp ( $\underline{\mathrm{BBC}}, \underline{2019})$. While this merging of multiple sites (with, potentially, different audiences) might not seem problematic in a world of a "single, authentic identity" envisioned by Facebook's CEO Zuckerberg, there is considerable evidence that a "single identity" is neither natural nor usual in offline life.

There has been extensive prior research into the "multiple audience problem" posed by social media (e.g., Colliander et al.,2017; Marwick \& Boyd, 2011). Content and selfpresentation management has been extensively discussed regarding professional identities, where there is constant interplay between the user performing for themselves alongside representing their employer, whereby balancing potentially differing expectations. This balance can take a toll (e.g., causing stress, fatigue, or fear), partly also due to the continuous construction and performance of multiple presentations online (Jin et al.,2014; Kasperiuniene \& Zydziunaite,2019; van Dijck,_ 2013). The presence of multiple audiences on social media sites means that users have to actively monitor their self-presentation in order to meet the different expectations of diverse groups, potentially leading to social anxiety, problems with social relations (Binder et al.,2009; Marder et al.,2016; Rui \& Stefanone,_2013; van Dijck, 2013).

Other research has also considered this separation in terms of private and public spheres and their role in the construction and maintenance of social media identities and the boundaries between them (Kasperiuniene \& Zydziunaite,_2019; Lehti \& Kallio, 
2017). Hence, the personal narratives created for various social media identities are crucial in terms of identity construction. Presenting multiple facets of ourselves is not well supported on most single services, in part because group systems are underutilized, and users are far more likely to self-censor rather than to utilize audience management tools on social media platforms (Fiesler et al.,2017). This is also known as the "lowest common denominator" effect where the most easily offended audience acts to "chill” expression (Marder et al.,2016), meaning that online audiences to act as a type of information control (Fiesler et al.,2017; Hogan, 2010). This "context collapse" (ㅁoyd \& Ellison, 2007) leads individuals to only share content and information that is deemed acceptable to the broadest audience within their network.

Therefore, perhaps users adopt different social media sites for distinct audiences and purposes as there is a constant changing of the self as we shift, change, and adapt our

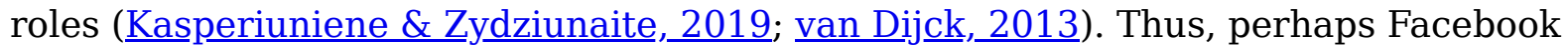
becomes the location for family and friends to keep in touch, LinkedIn becomes the place to build professional networks, Twitter becomes the site of choice for topic-based arguments with strangers, and Instagram is used for subtle flirtation and "cyberstalking." Indeed, anecdotal and published evidence suggests that social media is gradually becoming atomized in such a way (ㅂoyer \& Steyaert,_2015; Kasperiuniene \& Zydziunaite, 2019), with Snapchat becoming (perhaps temporarily) the site of choice for building relations with people known offline (iwek \& Joinson, 2016), LinkedIn continues to advertise itself as the "world's largest professional network," in comparison to other apps or range of sites used for sexual expression and flirting (e.g., Tinder, Grindr) (Albury, 2017). Hence, there are nuances to how users negotiate their identities, whether content is cross-posted and when (especially with increasing integration of services), and how their perceptions change when you can be "nameless" on a platform (e.g., Reddit, Instagram to an extent but it links with Facebook accounts). We know little about how people negotiate the potential discrepancies in their identity performance across multiple sites and services, what the impact of shared (or distinct audiences) might be, and what the challenges of unifying systems might be. Certainly, it is conceivable that users embrace uniform selfpresentation across multiple systems. However, given the differing system designs, goals, and audiences of sites, we suspect that this is unlikely to happen (Levina \& Arriaga, 2014). Instead, we anticipate that users will have a variety of strategies for managing multiple audiences across multiple sites that reflects the likely audience(s), 
the publicness of the platform and content, use of your real identity, and the perceived purpose for the platform.

In the present research, we explore how people negotiate self-presentation and social roles across multiple sites. In particular, we are interested in the balance of audience, norms, and purpose of the service. Hence, we are exploring whether users will delineate specific platforms (despite increasing integration between platforms) for specific audiences. This in turn will reveal more nuanced understanding of how platform ecologies (e.g., Facebook and Instagram becoming highly integrated) relate to blurring of audiences with contacts being suggested across platforms. This provides insight into how users will negotiate context collapse and the shape shifting of their self-presentation to mitigate this.

\section{Methods}

Given the exploratory nature of the research, we began with semi-structured interviews regarding participant's use of social media and communication platforms. We then used a well-established elicitation method-the repertory grid technique (RGT; Kelly, 1955) - in order to reveal key similarities and differences across multiple platforms. This technique has been used across a variety of contexts from marketing (e.g., Lemke et al.,2011), information systems (e.g., Tan \& Hunter, 2002), to software engineering (e.g., Edwards et al.,_2009).

This study was ethically approved by the University of Bath and was conducted in accordance with the ethical guidelines of the British Psychological Society (BPS). Institutional Review Board (IRB) approval was not necessary for this study.

\section{Participants}

Twenty-two participants (14 female; mean age $=28.22$; range $=22-39$ ) participated in 2017. Most participants were current students at the University of Bath. They were recruited via word-of-mouth and snowballing. Out of the 22 participants, one participant did not provide output for the RGT. The participants were mostly European, with two Chinese students and an American. All participants took part voluntarily.

\section{Semi-Structured Interview}

Upon arrival, we provided each participant with a series of flash cards with the names of various social networking sites (SNSs) and social media services (e.g., Facebook, Instagram, LinkedIn, Snapchat, WhatsApp, Twitter, and Reddit); other cards were 
added if required. The participant was asked to give an overview of their online social media usage. They were then asked about why they still use platforms, why they subsequently deleted accounts, and about content shared on each account. Questions were asked about their audience and contacts, followers, or "friends," and any concerns they had online. The interviews lasted approximately 40 to 50 minutes. The interviews were fully recorded and transcribed. For interview analysis, we used Braun \& Clarke, 2006 Thematic Analysis Technique and NVivo to identify and cluster themes. This method was used for several reasons:

1. It is widely used for qualitative research and is a well-known method across social sciences (Braun \& Clarke, 2006; Nowell et al.,2017).

2. It offers considerable freedom and flexibility, which allows for rich insight (Nowell et al.,2017).

3. It is well suited to exploratory research where there is little existing research.

\section{Repertory Grid Technique}

Once the interview had finished, we moved onto the RGT, which were designed by $\underline{\text { Kelly, } 1955}$ to elicit personal constructs. Repertory grids (RGs) have since been used widely in clinical psychology (Björklund, 2008). There are three components of RGs (Kelly,_1955; Tan \& Hunter, 2002):

1. Elements: The object or context of the research (typically people or versions of the self; for example, ideal, real) in counseling settings. In the present work, each element is a social media service that the participant uses frequently.

2. Constructs: The participant's interpretation of how a selected triad of elements are similar or different (typically bipolar such as "private-public").

3. Links: The way in which all elements relate to constructs.

We have integrated the RG technique with interviews as RGs help to elicit these constructs when linked with an interview as it allows the individual time to consider and reflect on their uses of social media when they may not have explicitly verbalized these personal constructs prior to the interview (Björklund, 2008). Hence, the data obtained will be rich and allow for both qualitative insights and quantitative insights (e.g., using Euclidean distances to compare platforms based on individual's personal constructs elicited).

RGT Method. Participants were asked to choose the top 8 to 10 social media platforms they used from a selection of flash cards. The cards were then shown in sets of three to the participant, who was then asked: "Which two are similar, and by the same token, 
the third is different, and why?" The reason given for the similarity/difference was recorded as a "construct." As noted, constructs are bipolar in nature (ransella et al., 2004; Kelly,_1955; Tan \& Hunter,_2002), for example, public-private and truthfuldishonest. Each construct is unique to each participant. We continued to cycle through these cards in unique triads until no new constructs were generated and began to repeat.

Next, participants were asked to select their top five-used social media platforms. Then, we used the constructs previously elicited in order to rank each of the five platforms in terms of each construct. For instance, if a construct was "professionalsocial," the participant ranked each platform from the most professional to the least professional in terms of their usage. These scores were then used to calculate Euclidean Distances between the services for each participant (see next section for dendrograms of some participants). This process was also fully recorded and transcribed alongside the interviews.

Table I. Most Common Constructs from the Ranking Stage of the RGT Method (Used for the Euclidean Distance Metrics) for the Most Common Platforms of the Participants in This Study.

\begin{tabular}{|c|c|}
\hline Platform & Common constructs from RGs \\
\hline Facebook & $\begin{array}{l}\text { Public; for entertainment and procrastination; self-reported high use; negative emotions (e.g., stressful); for lurking or } \\
\text { "Facebook stalking"; memory log; content and information searching; obliged to have; memory log; social }\end{array}$ \\
\hline WhatsApp & $\begin{array}{l}\text { Direct and private communications; high use; authentic; obliged to have; obliged to reply quickly; for entertainment } \\
\text { and procrastination; all types of communication (e.g., family, social, professional) }\end{array}$ \\
\hline Email & Private; professional; self-reported high use; obligation to have; physically knowing contacts offline; information search \\
\hline YouTube & $\begin{array}{l}\text { For entertainment and procrastination; lurking; for information/content consumption; typically, self-reported long } \\
\text { usage }\end{array}$ \\
\hline Instagram & $\begin{array}{l}\text { Public; negative emotions (e.g., depressing); positive emotions (e.g., excitement to use, motivational); entertainment; } \\
\text { memory log; ideal self; regulated posts; social }\end{array}$ \\
\hline Twitter & Regulated posts; professional; positive emotion (e.g., enjoyment); for information searching; aware of self-presentation \\
\hline
\end{tabular}

Note. RGT = repertory grid technique; RGs = repertory grids.

\section{Findings and Discussion}

The most common (mentioned by more than three participants) social media or communication tools chosen in the RGT phase of the study for men were Email, YouTube, Facebook, and WhatsApp. For female participants, the most common (mentioned by at least three participants) platforms used in the RGT phase were Facebook, WhatsApp, YouTube, Email, Instagram, and Twitter. There were a number of common constructs elicited from the RGs (Table 1), including the distinction between public and private spheres, how often and how long participants self-report using these 
platforms, how they use platforms (e.g., both Facebook and Instagram were often viewed as a memory log), and how content is developed for platforms.

\section{Maintaining Boundaries Across Platforms}

The perhaps most common theme that arose from the interviews and RGs was the notion of an audience-“who is watching me?" and therefore, how users regulate their self-presentation in tandem. All but two participants reported that they attempted to maintain a separation between their professional- and social-oriented platforms. However, P10 and P18 attempted to maintain a "personal brand," where they sought to maintain similar profiles across platforms regardless of the platform itself. There was substantial agreement between participants on which platforms were associated with professional or social usage (e.g., professional: LinkedIn and Academia.edu; social: Facebook and Snapchat). Unsurprisingly, Facebook was the most common social media platform for participants to have or had; it was also named as "the most traditional" social networking platform. Participants reported that their use of Facebook was primarily social and was often kept separate from professional platforms (see Figures 1 and 2)

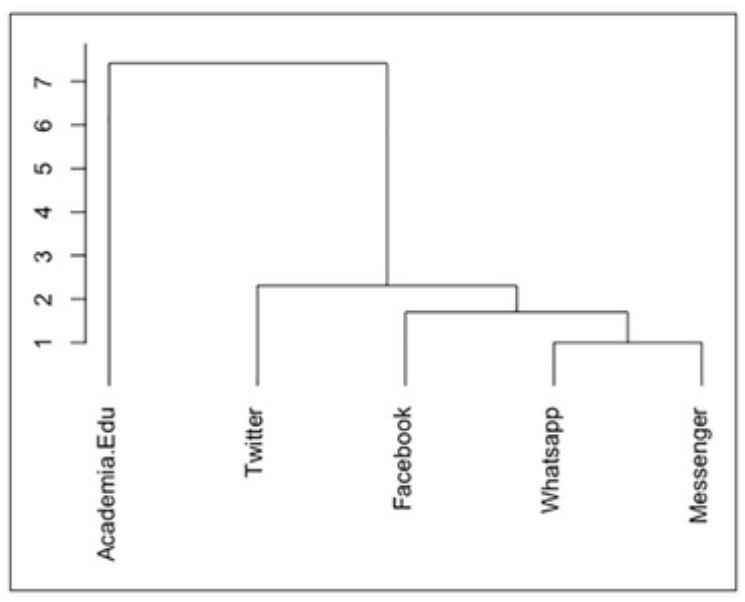

Figure I. P20's Euclidean Distance based on personal constructs from the RGs.

Note. Graph shows the first split between Academia.edu and Twitter, showing the professional versus social boundary. With the following social media platforms, Facebook, WhatsApp, and Messenger being similar in terms of her constructs, and were all regarded as social. RGs = repertory grids.

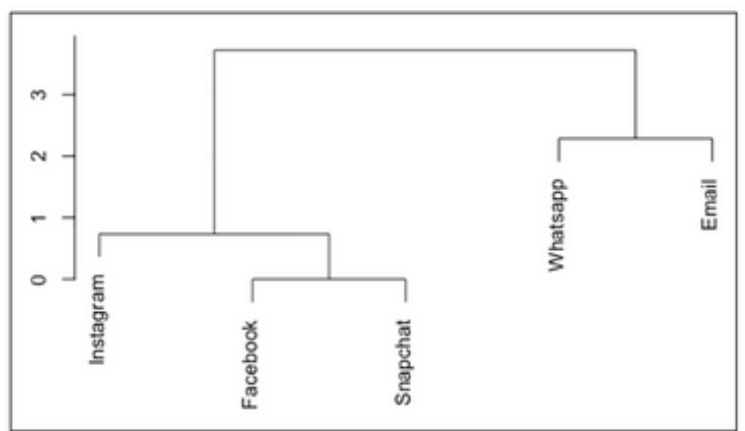

Figure 2. PI6's Euclidean Distances based on personal constructs from her RG. Note. Here, we can see a cluster of platforms in the lower LHS of Facebook, Instagram, and Snapchat denoting similar usage of social media platforms, and in contrast WhatsApp and Email with a professional focus in comparison. RG = repertory grid; LHS = left-hand side.

Professional-Social Life Boundaries. The distinction of private and public spheres from participants demonstrates a split between what the audience (friends or followers) expect as finely curated content versus a direct discussion with someone (or a small 
group of people). This, of course, relates back to $\underline{\text { Hogan, }} \underline{2010}$ notion of curation online, where participants will curate their profile, particularly in places such as Instagram, in order to exhibit their online identity as they wish. However, this is not to suggest that there is no curation within direct communications, where a person would naturally adapt their conversations with another person, as the curation of content is not only about the context (e.g., platform), but critically, it is about the individuals involved (Hogan, 2010). Hence, unsurprisingly, participants often reported feeling uncomfortable when these boundaries were blurred. This aligned with Goffman's description of audience segregation breakdown leading to feelings of anxiousness ( $\underline{\text { Goffman, 1956) }}$, reflecting recent literature examining multiple audience management and social anxiety (e.g., Marder et al. (2012):

I always feel strange sending a message on WhatsApp to a supervisor or boss, as I might message and they're cooking dinner [. . .] it feels very personal, it doesn't feel quite right. (P4)

I try not to have colleagues [on] Facebook because it is supposed to be a place to vent. (P21)

Several participants reported having highly restrictive privacy settings on Facebook, so non-Facebook "friends" can see little on their profiles, which was often discussed in light of efforts to maintain a separation between their professional and social lives. Many participants simply refused or ignored friend requests from work-based contacts on Facebook as opposed to utilizing content filtering options native on the platform, which aligns with prior research reporting a lack of engagement with audience management tools (Marder et al. (2012). One participant, P6, was the only interviewee who utilized Facebook's privacy settings to manage audiences within the site-in her case limiting access to albums with photos of her daughter to family members only. Maintaining a virtual distance between colleagues (e.g., by refusing/ignoring friend requests) perhaps creates a "safer" environment and less need to worry if a user forgets to use the content filtering (Karl et al.,2017). However, Batenburg_and Bartels (2017) have found that integrating wider audiences (e.g., work colleagues) onto Facebook and therefore curating content for a wider audience increases likability (by letting people get closer and into friendship circles) in comparison to segmentation strategies as seen in the present sample. The findings from Batenburg and Bartels (2017). provide some evidence for the "one identity" described by Zuckerberg (as reported by Zimmer (2010)), however this potentially creates a chilling effect online, 
where users may post less or withdraw to avoid overestimating their new-founded audience with work colleagues.

For example, P1 stated that his use of Facebook and WhatsApp were for more "serious" communication. From his RG (Table 2), we can see a split between public versus private as well as professional versus social platforms, where media types such as Skype, Email, and LinkedIn all are heavily associated with professionalism. However, unsurprisingly, Facebook and LinkedIn require personae development and management. While the overall "goal" or motivations of use may indeed be different, they require similar initial input from users to develop various personae. In contrast to more "serious" platforms, P1 stated he enjoyed Snapchat and saw it as distinctive because he enjoyed its flippant, fun, and disposable nature in comparison to other social media platforms such as Facebook. This distinction reflects previous work on the value of playful (disposable) platforms-what we might think of as having "warm" communications-in building bonds between people (iwek \& Joinson, 2016). This also is an example of a participant that perhaps would have less concerns having work colleagues or bosses as a "friend" on Facebook due to their more serious selfpresentation but have more concerns if a work colleague or boss were a contact on Snapchat, which is far less censored.

Table 2. A Snippet of PI's RP Table of Bipolar Constructs Relating to Differences Across Platforms in Terms of Self-Presentation and Audience Management.

Construct Media type

YouTube Facebook SnapChat WhatsApp Email Linkedln SMS Skype Twitter Vimeo

Permanent (o) versus disposable content $(\mathrm{x}) \quad 0 \quad 0 \quad 0 \quad x$

Public (o) versus private $(x)$

Public (o) versus private $(\mathrm{x})$

Professional use (o) versus social $(x)$

Professional use $(0)$ versus social use $(x)$

Built a persona (o) versus no persona built $(\mathrm{x})$

Note. 0 denotes similar platforms; $x$ denotes the dissimilar platform. SMS = short message services.

Permanence of Online Artifacts. Other participants managed social-professional audience tensions by carefully managing their posting behavior-for instance, P20 reported that she "used to be more provocative" but now vets her posts since she has several colleagues or bosses as "friends" online, and did not want to share anything "embarrassing" or "too revealing." P1 was also wary of Facebook posts as they allowed for (often critical) feedback and noted that this content is "permanent" from his RG (Table 2). This is also an example of "time collapse" - defined as muddled boundaries 
between the past and present. Both P20 and P1 discussed changing their online posting behavior, similar to Brandtzaeg_\& Lüders, 2018 comments relating to cleaning up of social media provides to provide a "polished self-presentation" as a result of reflecting on past behavior online (DeVito et al.,2018).

Permanence of posts, especially on older platforms, is a concern reported across the literature, particularly in terms of identity transitions during childhood and adolescence (Brandtzaeg_\& Caparro-Dominguez,2020; Brandtzaeg_\& Lüders,_2018). While some research has shown that some participants are fond and reflective of how they portrayed their past identities, where they may not feel a need to edit or erase these memory logs; however, this was not always be the case (Bates et al.,2020). For instance, online identity archives undoubtedly capture artifacts that can sometimes raise privacy concerns (Brandtzaeg_\& Caparro-Dominguez, 2020; Brandtzaeg_\&

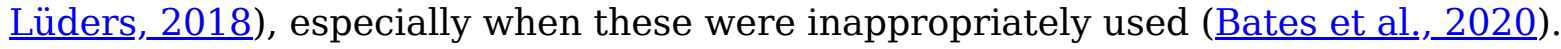
For example, P6 described her "creepy experience," with one of her professional headshots, which was named firstname_surname for her convenience. P6 had googled herself to check what returns, and to their disturbance, a website called "Women That I Would Do" appeared. P6 was quick to clarify the sexual nature of this site, which contained pages full of folders containing thousands of photos of women, categorized by type, for example, the "blondes" and the "big-boobed ones." P6 sadly stated, "I think the vast majority of the women on there had no idea. It's creepy . . " Of course, her seemingly convenient photo naming meant this photo was searchable on the site based on the image metadata. P6 expressed concern that her employer might have seen this before the request removal of her photo had been completed. This is an example of an unpleasant privacy issue that could have ramifications for her professionally, socially, and for her well-being and feeling of safety. Especially noting she stumbled on this by accident, which raises the importance of digital and privacy literacy online for all ages (perhaps most critically, children; Livingstone et al.,2020).

\section{Pressure to Perform}

Self-regulation of content was often discussed in relation to social accounts in order to avoid conflict online or self-regulation of their physical image in photos/videos. For example, P12 expressed concerns about photos being uploaded from nightclub Facebook accounts after a night-out, or "friends" tagging photos of her looking "ugly"; hence, she had fairly strict "unspoken rules" regarding what, when, and where she posts her content (Table 3). In contrast, P19 reported she cross-posted everything between Facebook and Instagram despite the overlap in friends/followers and there 
was no distinction in content. She described her accounts as having, "all of my photos and selfies" as it is her way "to express [her] feelings." This intense sharing behavior has been linked with increased well-being, where this sharing of information is therapeutic and aids emotion regulation, especially after negative experiences (Buechel \& Berger, 2012). However, other scholars suggest these "updates" reflect narcissism and vanity (DiSalvo, 2010), which were reflected in some participant views on "friends" posting heavily online.

Table 3. A Snippet of PI2's Rep Grid Table of Bipolar Constructs Relating to Differences Across Platforms in Terms of Her Awareness of Her Self-Presentation and Where She Maintains Personae Versus When She Does Not.

\begin{tabular}{|c|c|c|c|c|c|c|c|}
\hline \multirow[t]{2}{*}{ Construct } & \multicolumn{7}{|c|}{ Media type } \\
\hline & Twitter & Instagram & Facebook & Pinterest & Linkedln & SnapChat & YouTube \\
\hline $\begin{array}{l}\text { Aware of self-presentation (o) } \\
\text { versus less relfection of self- } \\
\text { presentation }(x)\end{array}$ & & 0 & 0 & $x$ & & & \\
\hline Social use $(0)$ versus professional $(x)$ & 0 & & 0 & & $x$ & & \\
\hline $\begin{array}{l}\text { Aware of self-presentation }(0) \\
\text { versus less reflection of self- } \\
\text { presentation }(x)\end{array}$ & 0 & & 0 & & $x$ & & \\
\hline $\begin{array}{l}\text { Has an audience }(0) \text { versus no } \\
\text { audience }(x)\end{array}$ & & 0 & & & & 0 & $x$ \\
\hline
\end{tabular}

Note. 0 denotes denotes similar platforms; $x$ denotes the dissimilar platform

P2 welcomed less edited and more realistic portrayals on Facebook, "so you can go back and have memories [that] I remember," rather than "looking back at a lot of photos that you've tried to make different from [. . .] reality." This reflects the importance of self-presentation and the way users believe they are being perceived by their audience(s). For some participants, it was clear there were subtle differences in self-presentation between Facebook and Instagram. For instance, while P12 used Instagram frequently and there was some overlap between Facebook and Instagram content, all photos from a night-out or a holiday would be posted to Facebook, while Instagram only received the "best photo." Typically, Instagram (more so than Facebook) was consistently stereotyped as a "heavily edited version of your life," and a "perfect world" portrayal online. P4 maintained a different form of separation between her Instagram and Facebook posts, with Instagram focusing on food, drinks, and art, which she believed is more suitable for her Instagram audience and personae. Her posts were only occasionally cross-posted to Facebook if "friends" were tagged in photos. This almost automatic set of behaviors to adapt content across platforms demonstrates that the notion of a single, authentic identity based on Facebook 
suggested by Mark Zuckerberg as reported by Zimmer (2010). will be a challenge and remains arguably unnatural.

Critical Feedback. Other participants were aware of critical feedback afforded across public platforms such as Twitter and therefore had various strategies to handle this. For instance, P20 maintained two Twitter accounts, one for work and a personal account, where she tweeted about politics and actively engaged in Twitter arguments. These two accounts were also kept separate via different usernames. This indicates that participants actively created and maintained boundaries both between and within their social media accounts. Most participants at some point were critical over their "friends" or those they follow. Several participants commented on others oversharing across social media platforms, which was not typically well received. For example, P7 described her "annoying friend" that continues to post "tens of baby photos every day"-although this did not deter her (and other participants) from remaining engaged online but rather caused anger and annoyance. This is also an interesting lack of user filtering their online news feed or simply unfollowing particular users, which shows there may be underlying social obligations that participants felt they needed to fulfill or that it is easier to remain a follower to avoid any conflict (DeVito et al.,2018).

Playing to an audience over being authentic was not typically regarded well by participants. Several participants claimed Instagram was about "building up a fake lifestyle," which made it difficult to distinguish actual (photography) skill from "too many filters"-where "everyone believe[s] they're a professional photographer." Yet, the participants reporting this concern still had accounts-even if they were not frequent users. This may relate to the notion of the "fear of missing out" (FOMO), which is defined by "the desire to stay continually connected with what others are doing" (Przybylski et al.,2013, p. 1841), as these accounts-despite some reported infrequent use-allowed users to maintain a silent presence and connection to "friends" or followers (akin the "social stalking" discussed in early studies of Facebook use; Ellison et al.,_2007; Joinson,_2008). However, other participants reported that they would unfollow updates from people who they deemed as oversharing, suggesting some form of calculus between the value of passive social information consumption and the need to manage the over-production of information by selected people. In contrast, the notion of imposed or expected curation from a platform or audience also did not always sit well with participants, where maintaining a persona for particular platforms felt forced, for example, P6 stated, 
I have a profile [LinkedIn][. . .] I feel like a bottle of shampoo marketing myself on there [...], I think it's a lot of lies and untruths.

This shows that user willingness to perform and maintain both their persona or profile is also influenced by the others using this platform, and whether these platforms remain useful. For instance, P4 stated feeling unmotivated to engage with LinkedIn: 'I am pretty half-assed maintain[ing] a profile, I don't really engage on there.' It was common for participants to state that LinkedIn was obsolete and other platforms, such as Twitter, were overtaking it for professional purposes.

Self-presentation behaviors are critical for forming outside impressions, where social media allows us to emphasize and explore new facets of ourselves or to be someone entirely different-should we want to (Papacharissi, 2002; Vohs et al., 2005). However, when there are clear discrepancies (known to the user or not), there can be audience clashes, where the user will receive potentially negative feedback due to these discrepancies. For example, P10 used Instagram to show her makeup artistry portfolio and as this developed over time, she began to experiment with different makeup styles: "I started doing drag makeup, and that upset quite a few people,"-this of course "rocked the boat" as these new images were outside of her audiences desired range, meaning a lack of maintaining "peacekeeping" self-presentations" (Brandtzaeg_

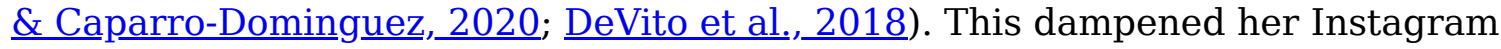
experience to the point that she deleted her account as she felt the need to "micromanage" her content and it became "very unnatural." This demonstrates that while one can creatively build their self-presentation, the audience is also a key component of this identity development and this can, of course, go wrong (Belk, 2013), which raises questions around audience and platform tolerance, and the impacts of this on the curator.

Creative Secrecy and Hiding Online. Many participants revealed "creative" constructs during the RGT phase of the interview, where the idea of "inspiration" seeking was extremely common. This was primarily associated with highly visual platforms, such as Instagram, Pinterest, and YouTube. Other participants took advantage of anonymity to avoid audience mismatches or revealing too much about themselves particularly relating to creative outlets. For instance, P3 used an anonymous account on DeviantArt for his personal poetry (Table 4). He kept this poetry account entirely hidden due to his uncomfortableness of peer-to-peer surveillance, and he noted that he did not want this personal content shared with his Facebook "friends" or audiences. 
Table 4. A Snippet of P3's Rep Grid Table of Constructs Relating to Creativity and Media Platform.

\begin{tabular}{|c|c|c|c|c|c|c|c|c|}
\hline \multirow[t]{2}{*}{ Construct } & \multicolumn{8}{|l|}{ Media type } \\
\hline & Facebook & Email & YouTube & Skype & WhatsApp & Linkedln & DeviantArt & SMS \\
\hline $\begin{array}{l}\text { For creativity }(0) \\
\text { versus non-creative } \\
\text { platforms }(x)\end{array}$ & 0 & & & & $x$ & & 0 & \\
\hline $\begin{array}{l}\text { Professional use }(0) \\
\text { versus social }(x)\end{array}$ & & $x$ & & 0 & & 0 & & \\
\hline $\begin{array}{l}\text { Not for self-expression } \\
\text { (o) versus for creativity } \\
\text { (x) }\end{array}$ & & 0 & & & & & $x$ & 0 \\
\hline
\end{tabular}

Note. 0 denotes denotes similar platforms; $x$ denotes the dissimilar platform. SMS $=$ short message services.

Alongside using platforms as a way to channel a creative outlet (e.g., P3 and P8 in particular), many participants discussed how they use a variety of platforms for entertainment and creative or beautiful content consumption. This often came hand-inhand with passive usage or lurking behaviors rather than a pressure to perform for an audience. For example, P15 and P8 (Figures 3 and 4) stated their primary use of YouTube, Reddit, and Forums was recreational and for content consumption, which then also meant that his self-reported time spent on these three platforms was the highest and most intense. However, it is important to note that this was not objectively measured and may not be reflective of actual usage patterns (Ellis et al.,2019; Parry et al.,2020). It was also common for participants to use these kinds of content consumption-based platforms for "procrastination" via lurking (Table 1).

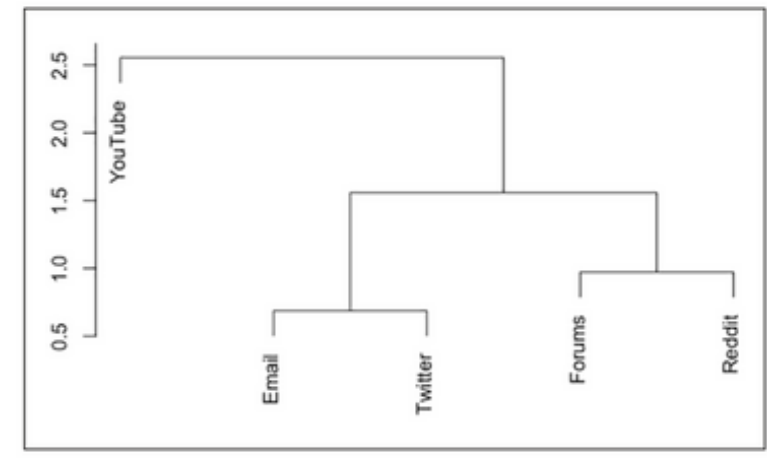

Figure 3. PI5's Euclidean Distance based on personal constructs from the RG.

Note. Overall, it shows similarity between Reddit and Forums (based on use for entertainment, length of time, and anonymity), whereas Email and Twitter were similar in usage (based on the lack of anonymity and variety in content consumed during use). RG = repertory grid.

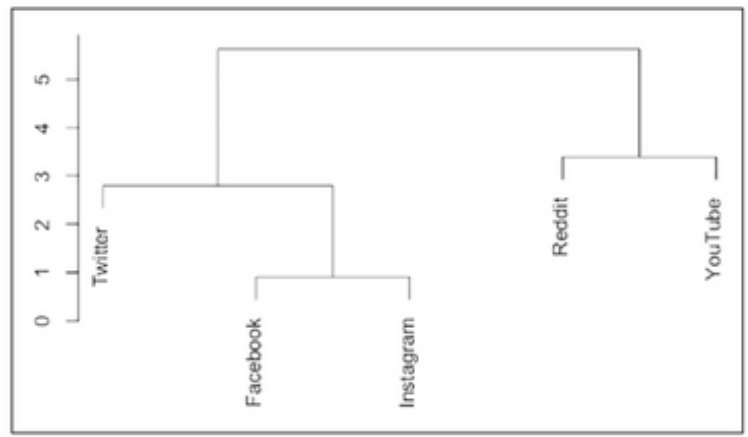

Figure 4. P8's Euclidean Distance based on personal constructs from the RG.

Note. Overall, it shows similarity between Reddit and YouTube in one cluster and then Facebook, Instagram, and Twitter in a second cluster. $\mathrm{RG}=$ repertory grid. 


\section{Study Limitations}

There are some limitations of this study. First, it must be noted that the data were collected in 2017, where a number of features and changes across social media platforms have been updated. For instance, while many users discussed distinctions between direct messaging platforms (e.g., WhatsApp) and others for only broadcasting (e.g., Snapchat), we acknowledge some of these platforms now have both capabilities (e.g., WhatsApp and Twitter have the newly integrated "stories" features, or Fleets in the case of Twitter, like Facebook and Instagram). However, the nuances found regarding shifting self-presentation and strategies to maintain virtual boundaries will remain salient, if not more so as these services are increasingly interlinked and integrated. Second, many participants discussed their "usage" of various platforms. It is important to note there is a distinct difference between self-reported usage of platforms versus their objective use, where we have sought to highlight this, as it is

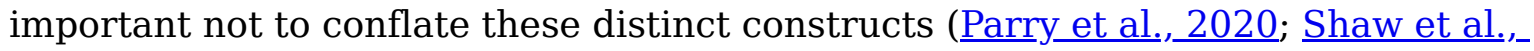
$\underline{2020})$.

\section{Conclusions and Future Research Directions}

This article intended to extend knowledge regarding social media identity and selfpresentation negotiation across various social media platforms. We anticipated participants would have various identities and self-presentations online. Hence, we expected participants would have several strategies to manage multiple audiences across multiple platforms that reflects audience expectations; the level of privacy users wish to maintain for their profile; the use of their real identity (e.g., using their actual name); user perception of the purpose of the profile; and social norms naturally residing in the site. It is curious to compare various individual's usages across platforms, as platforms are typically increasing their functionality to compete with one another. Noting that Facebook owns both Instagram and WhatsApp, it is of no surprise that they all share functionalities and features (e.g., direct messaging, image, video, and "stories"). However, Twitter added their "Fleets" functionality in 2020 to mimic Facebook, Instagram, and WhatsApp stories. This raises interesting questions regarding whether social media platforms can still be categorized for a certain set of purposes anymore. For instance, we found Facebook and Instagram were initially meant for social purposes but have since branched out to include shopping and company pages, which widens the types of usage beyond simply "social." Twitter was perhaps less defined but is commonly used for work and news in our sample, but of course this works alongside other uses not captured here, for example, social uses, 
social influencing, cross-promotion of influencers' other pages, such as OnlyFansagain, demonstrating a wide variety in purposes. Hence, there appear to be less nuances in social media platforms that once made them unique, including the way these platforms now look. It is important to note that social media platforms are dynamic and ever-changing, whereby users will continue to shape-shift their selfpresentation according to how they wish to use various platforms, which may include shifting away from a particular platform altogether. Currently, it does appear that platforms are wanting to conform to the notion of "one identity" online based on design decisions that have been recently implemented. However, more work needs to better understand user perceptions of this.

Despite this, and noting data were collected in 2017, we found that participants still appeared to delineate platforms for specific purposes (e.g., professional, for creativity, for social contexts). Users did report that certain platforms "required" a persona (e.g., Facebook or Instagram), while others were more authentic for them (e.g., WhatsApp), which seemed to have a link with how direct the communications are (e.g., primarily for one-to-one conversations). Furthermore, many participants in the RG stage gave examples of platforms built for "broadcasting." One of the more common examples was Snapchat due to its ability to send "snaps" to both friends and more publicly. The notion of broadcasting was made often in comparison to more direct communication tools such as WhatsApp (noting WhatsApp's "stories" feature came after these data were collected) or short message services (SMS). The contrast between broadcasting and direct (often one-to-one) messaging also related to how personal (or private) various platforms were for each participant; hence, the notion of being "personal in mass communication" emerged within the RG phase.

Almost all participants separated their professional and social selves across various social media platforms. This shows that to a certain extent, all participants did maintain several self-presentations across multiple platforms. In terms of professional platforms, naturally, LinkedIn, Academia.edu, and often Twitter were commonly associated. Participants shared less intimate and detailed information as these platforms are almost exclusively public. This self-regulating behavior typically aligns with Bazarova and Choi's (2014). and Gonzales and Hancock's (2008). distinctions between information shared across public and private online platforms. When participants reported being an active user of a platform, many stated they engaged in some level of self-regulation and self-censorship regarding their online presence, and it was found participants often shared different content across each site. Self-regulation 
of posts was more commonly reported in relation to Instagram and Twitter, which is perhaps linked to the idea of having an audience or "following."

This work revealed some nuances of how participants actively perceived their usage across a number of media and technology platforms, where we note additional subtly differences between Facebook and Instagram use despite them both being typically socially oriented platforms. For instance, Facebook was often regarded more realistic, natural, or "authentic." In comparison, Instagram tended to receive the most polished images and content shared was more "artsy" or kept to certain themes (e.g., food). This further aligns with the theory of the lowest common denominator ( and the notion of "collapsed contexts" (므yd \& Ellison, 2007), and actually "collapsed time” (Brandtzaeg_\& Lüders, 2018). Interestingly, some participants discussed anonymity of platforms, for instance, Reddit, YouTube, and online forums, where these were often used for a variety of content to consume and enjoy privately. While there are tools inbuilt to restrict friend/ contact access to posts, these tools were vastly underutilized, aligning with Marder et al.(2012). Participants preferred to un-tag or delete old content ("polished self-presentation"; DeVito et al., 2018), refrain from posting, or deliberately refuse "friend" or contact requests from colleagues or bosses, most commonly on Facebook. This further shows that a single online identity is arguably not viable, and this may lead to user uncomfortableness regarding to selfpresentation across online contexts.

This article sought to provide a novel approach to explore online settings by utilizing the RGTs alongside semi-structured interviews, specifically here, social media identities and self-presentation across platforms. We found that participants do maintain multiple presentations of self across multiple sites, and do engage in a set of

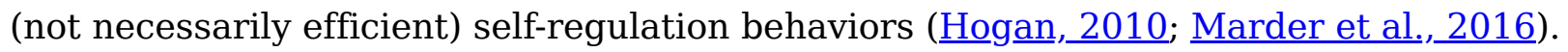
We find that there are many factors that impact participant behavior and engagement online. Understanding online behavior is complicated and clearly changes from platform to platform, and while we found overlap between our participants, their individual usage and reasoning behind it was unique.

\section{Declaration of Conflicting Interests}

The author(s) declared no potential conflicts of interest with respect to the research, authorship, and/or publication of this article. 


\section{Funding}

The author(s) disclosed receipt of the following financial support for the research, authorship, and/or publication of this article: This work was part-funded by the Centre for Research and Evidence on Security Threats (ESRC Award: ES/N009614/1), www.crestresearch.ac.uk. The funders had no role in study design, data collection and analysis, decision to publish, or preparation of the manuscript.

\section{Author Biographies}

Brittany I. Davidson (PhD, University of Bath) is an assistant professor of analytics at the University of Bath and an honorary lecturer in Digital Health at the University of Bristol. Her work focuses on how we can use digital traces to better understand people and patterns of behavior with applications in both security and health.

Adam N. Joinson (PhD, University of Hertfordshire) is a professor of information systems at the University of Bath. His work conducts interdisciplinary research on the interaction between human behavior and technology, with specific foci on issues of how the design of systems influences behavior ranging from privacy and selfdisclosure, cyber-security, social relations, and patterns of influence.

\section{REPRINT}

"Shape Shifting_Across Social Media" (Brittany I. Davidson and Adam N. Joinson, Social Media + Society 7, no. 1, February 18, 2021)

OPENLY LICENSED

\section{Citations}

1. Zimmer, M. (2010). Facebook's Zuckerberg: "Having two identities for yourself is an example of a lack of integrity." http://www.michaelzimmer.org/2010/05/14/facebooks-zuckerberg-having-twoidentities-for-yourself-is-an-example-of-a-lack-of-integrity $\perp$ ㄴ

2. Dellarocas, C. (2003). The digitization of word of mouth: Promise and challenges of online feedback mechanisms. Management Science, 49(10), 1407-1424. https://doi.org/10.1287/mnsc.49.10.1407.17308

3. Loebbecke, C., \& Picot, A. (2015). Reflections on societal and business model transformation arising from digitization and big data analytics: A research agenda. 
Journal of Strategic Information Systems, 24, 149-157.

https://doi.org/10.1016/j.jsis.2015.08.002

4. Herrmann, T., Jahnke, I., \& Loser, K. U. (2004). The role concept as a basis for designing community systems. In Cooperative systems design, scenario-based design of collaborative systems (pp. 163-178). $\bullet$

5. Hogg, M., Terry, D., \& White, K. (1995). A tale of two theories: A critical comparison of identity theory with social identity theory. Social Psychology Quarterly, 58, 255-269. https://doi. org/10.2307/2787127

6. Fiske, S. T. (2010). Social beings (2nd ed.). Wiley. $\_$

7. Vasalou, A., \& Joinson, A. N. (2009). Me, myself and I: The role of interactional context on self-presentation through avatars. Computers in Human Behavior, 25(2), 510-520. https://doi.org/10.1016/j.chb.2008.11.007

8. Kasperiuniene, J., \& Zydziunaite, V. (2019). A systematic literature review on professional identity construction in social media. SAGE Open, 9(1).

https://doi.org/10.1177/2158244019828847

9. BBC. (2019). Facebook to integrate WhatsApp, Instagram and Messenger.

https://www.bbc.co.uk/news/technology-47001460

10. Colliander, J., Marder, B., Falkman, L., Madestam, J., Modig, E., \& Sagfossen, S. (2017). The social media balancing act: Testing the use of a balanced selfpresentation strategy for politicians using Twitter. Computers in Human Behavior, 744, 277-285.

11. Marwick, A. E., \& Boyd, D. (2011). I tweet honestly, I tweet passionately: Twitter users, context collapse, and the imagined audience. New Media \& Society, 13(1), 114-133. https://doi.org/10.1177/1461444810365313

12. Jin, Y., Liu, B. F., \& Austin, L. L. (2014). Examining the role of social media in effective crisis management: The effects of crisis origin, information form, and source on publics' crisis responses. Communication Research, 41, 74-94. https://doi.org/10.1177/0093650211423918 13. van Dijck, J. (2013). "You have one identity": Performing the self on Facebook and LinkedIn. Media, Culture \& Society, 35(2), 199-215. https://doi.org/10.1177/0163443712468605 
14. Binder, J., Howes, A., \& Sutcliffe, A. (2009). The problem of conflicting social spheres: Effects of network structure on experienced tension in social network sites. In Proceedings of the SIGCHI conference on human factors in computing systems (pp. 965-974). https://www.researchgate.net/profile/

Alistair Sutcliffe/publication/200048026 The problem of conflicting_social spheres Effects of network structure on experienced tension_in social_network sites/ links/543563380cf2bf1f1f2a32f0/The-problem-of-conflicting- social-spheres-Effects-ofnetwork-structure-on-experienced-tension-in-social-network-sites.pdf 15. Marder, B., Joinson, A., Shankar, A., \& Houghton, D. J. (2016). The extended "chilling" effect of Facebook: The cold reality of ubiquitous social networking. Computers in Human Behavior, 60, 582-592. http://opus.bath.ac.uk/49558/1/Chilling_Effect_CHB_revised_submission_BM.pdf 16. Rui, J., \& Stefanone, M. A. (2013). Strategic self-presentation online: A crosscultural study. Computers in Human Behavior, 29(1), 110-118.

https://doi.org/10.1016/j.chb.2012.07.022

17. Lehti, L., \& Kallio, J. (2017). Participation in an online social policy discussion: Arguments in focus. Discourse, Context and Media, 19, 58-65. https://doi.org/10.1016/j.dcm.2017.02.005 18. Fiesler, C., Dye, M., Feuston, J. L., Hiruncharoenvate, C., Hutto, C. J., Morrison, S., \& Glibert, E. E. (2017). What (or who) is public? Privacy settings and social media content sharing. In CSCW'17: Proceedings of the 2017 ACM conference on computer supported cooperative work and social computing (pp. 567-580). https://doi.org/10.1145/2998181.2998223 19. Hogan, B. (2010). The presentation of self in the age of social media: Distinguishing performances and exhibitions online. Bulletin of Science, Technology \& Society, 30(6), 377-386. https://doi.org/10.1177/0270467610385893 20. boyd, d., \& Ellison, N. B. (2007). Social network sites: Definition, history, and scholarship. Journal of Computer-Mediated Communication, 13, 210-230. https://doi.org/10.1111/j.1083- 6101.2007.00393.x 21. Hoyer, P., \& Steyaert, C. (2015). Narrative identity construction in times of career change: Taking note of unconscious desires. Human Relations, 68, $1837-$ 1863. https://doi.org/10.1177/0018726715570383 
22. Piwek, L., \& Joinson, A. (2016). “What do they Snapchat about?” Patterns of use in time-limited instant messaging service. Computers in Human Behavior, 54, 358367. https://doi.org/10.1016/j.chb.2015.08.026

23. Albury, K. (2017). Sexual expression in social media. In J. Burgess, A. Marwick \& T. Poell (Eds.), The SAGE handbook of social media (pp. 444-462). https://doi.org/10.4135/9781473984066.n25 24. Levina, N., \& Arriaga, M. (2014). Distinction and status production on usergenerated content platforms: Using Bourdieu's theory of cultural production to understand social dynamics in online fields. Information Systems Research, 25(3), 468-488.

25. Kelly, G. (1955). The psychology of personal constructs. W. W. Norton \& Company.

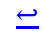

26. Lemke, F., Clark, M., \& Wilson, H. (2011). Customer experience quality: An exploration in business and consumer contexts using repertory grid technique. Journal of the Academy of Marketing Science, 39, 846-869. https://doi.org/10.1007/s11747-010-0219-0 27. Tan, F. B., \& Hunter, M. G. (2002). The repertory grid technique: A method for the study of cognition in information. MIS Quarterly, 26(1), 39-57. https://doi.org/10.2307/4132321 28. Edwards, H. M., McDonald, S., \& Michelle Young, S. (2009). The repertory grid technique: Its place in empirical software engineering research. Information and Software Technology, 51, 785-798. https://doi.org/10.1016/j.infsof.2008.08.008 29. Braun, V., \& Clarke, V. (2006). Using thematic analysis in psychology Using thematic analysis in psychology. Qualitative Research in Psychology, 3(2), 77-101. https://doi.org/10.1191/1478088706qp063oa $\leftrightharpoons$

30. Nowell, L. S., Norris, J. M., White, D. E., \& Moules, N. J. (2017). Thematic analysis: Striving to meet the trustworthiness criteria. International Journal of Qualitative Methods, 16(1). https://doi.org/10.1177/1609406917733847 31. Björklund, L. (2008). The repertory grid technique: Making tacit knowledge explicit: Assessing creative work and problem solving skills. In H. E. Middleton (Ed.), Researching technology education: Methods and techniques (pp. 46-69). 
32. Fransella, F., Bell, R., \& Bannister, D. (2004). A manual for repertory grid technique (2nd ed.). John Wiley. $\subseteq$

33. Goffman, E. (1956). Embarrassment and social organization. American Journal of Sociology, 62(3), 264-271.

34. Marder, B., Joinson, A., \& Shankar, A. (2012). Every post you make, every pic you take, I'll be watching you: Behind social spheres on Facebook. Proceedings of the Annual Hawaii International Conference on System Sciences, 2015, 859-868. https://doi.org/10.1109/HICSS.2012.12

35. Karl, K. A., Allen, R. S., White, C. S., Peluchette, J. V. E., \& Allen, D. E. (2017). Would you accept a Facebook friend request from your boss? Examining generational differences. International Journal of Virtual Communities and Social Networking (IJVCSN), 9(1), 17-33. $\leftrightharpoons$

36. Batenburg, A., \& Bartels, J. (2017). Keeping up online appearances: How selfdisclosure on Facebook affects perceived respect and likability in the professional context. Computers in Behavior, 74, 265-276. $\subseteq$

37. Brandtzaeg, P. B., \& Lüders, M. (2018). Time collapse in social media: Extending the context collapse. Social Media + Society, 4(1), 1-10.

https://doi.org/10.1177/2056305118763349 $\leftrightharpoons$

38. DeVito, M. A., Birnholtz, J., Hancock, J. T., French, M., \& Liu, S. (2018). How people form folk theories of social media feeds and what it means for how we study self-presentation. In Paper presented at the CHI conference on human factors in computing systems (p. 120). ACM. https://sml.stanford.edu/ml/2018/05/devito-chi$\underline{\text { folk. }} . \underline{\mathrm{df}} \leftrightharpoons$

39. Brandtzaeg, P. B., \& Caparro-Dominguez, M. (2020). From youthful experimentation to professional identity: Understanding identity transitions in social media. Young, 28(2), 157-174. https://doi.org/10.1177/1103308819834386 40. Bates, A., Hobman, T., \& Bell, B. T. (2020). "Let me do what I please with it . . Don't decide my identity for me": LGBTQ+ youth experiences of social media in narrative identity development. Journal of Adolescent Research, 35(1), 51-83. 41. Livingstone, S., Stoilova, M., \& Nandagiri, R. (2020). Data and privacy literacy: The role of the school in educating children in a datafied society. In The handbook of 
media education research (pp. 413-425).

https://onlinelibrary.wiley.com/doi/abs/10.1002/9781119166900.ch38

42. Buechel, E., \& Berger, J. (2012). Facebook therapy? Why people share selfrelevant content online. Advances in Consumer Research, 40, 203-208. http://www.acrwebsite.org/volumes/1012611/volumes/v40/NA-40 43. DiSalvo, D. (2010). Are social networks messing with your head? Scientific American Mind, 20(7), 48-55.

44. Przybylski, A. K., Koutamanis, M., DeHaan, C. R., \& Gladwell, V. (2013).

Motivational, emotional, and behavioral correlates of fear of missing out. Computers in Human Behavior, 29(4), 1841-1848.

45. Ellison, N. B., Steinfield, C., \& Lampe, C. (2007). The benefits of Facebook "friends": Social capital and college students' use of online social network sites. Journal of Computer-mediated Communication, 12(4), 1143-1168. https://doi.org/10.1111/j.10836101.2007.00367.x 46. Joinson, A. N. (2008). Looking at, looking up or keeping up with people? Motives and use of Facebook. In Proceedings of the SIGCHI conference on human factors in computing (pp. 1027-1036). https://digitalwellbeing.org/downloads/Joinson_Facebook.pdf $\leftrightarrows$ 47. Papacharissi, Z. (2002). Presentation of self in virtual life: Characteristics of personal home pages. Journalism \& Mass Communication Quarterly, 79, 643-660. 48. Vohs, K. D., Baumeister, R. F., \& Ciarocco, N. J. (2005). Self-regulation and selfpresentation: Regulatory resource depletion impairs impression management and effortful self-presentation depletes regulatory resources. Journal of Personality and Social Psychology, 88(4), 632-657. https://doi.org/10.1037/0022-3514.88.4.632 49. Belk, R. W. (2013). Extended self in a digital world. Journal of Consumer Research, 40(3), 477-500. https://doi.org/10.1086/671052 50. Ellis, D. A., Davidson, B. I., Shaw, H., \& Geyer, K. (2019). Do smartphone usage scales predict behaviour? International Journal of Human-computer Studies, 130, 8692. https://doi.org/10.31234/osf.io/6fjr $\underline{\text { 7 }} \uplus$

51. Parry, D., Davidson, B. I., Sewall, C., Fisher, J., Mieczkowski, H., \& Quintana, D. (2020). Measurement discrepancies between logged and self-reported digital media 
use: A systematic review and meta-analysis. Psyarxiv. https://psyarxiv.com/f6xvz/e

52. Shaw, H., Ellis, D. A., Geyer, K., Davidson, B. I., Ziegler, F. V., \& Smith, A. (2020). Quantifying smartphone "use": Choice of measurement impacts relationships between "usage" and health. Technology, Mind, and Behavior, 1(2). https://doi.org/10.1037/tmb0000022

53. Bazarova, N. N., \& Choi, Y. H. (2014). Self-disclosure in social media: Extending the functional approach to disclosure motivations and characteristics on social network sites. Journal of Communication, 64(4), 635-657. https://doi.org/10.1111/jcom.12106

54. Gonzales, A. L., \& Hancock, J. T. (2008). Identity shift in computer-mediated environments. Media Psychology, 11(2), 167-185.

https://doi.org/10.1080/15213260802023433 